\title{
Instintos en serie
}

\author{
The Fall $|\mathrm{BBC}| 2013$
}

Ariel Gómez Ponce

CONICET - Universidad Nacional de Córdoba

Recibido: 6 de abril de 2018; aceptado 17 de abril de 2018

\begin{abstract}
Resumen
Este artículo asume que el instinto propone una solución expeditiva para la cultura contemporánea, homogeneizando múltiples manifestaciones que van desde la intensidad protectora de lo maternal y la perdición irremisible de lo sexual, hasta el irrefrenable anhelo asesino. Nuestra hipótesis sostiene que esta categoría se conforma como un "andamiaje semiótico" cuya función sería la de traducir la irracionalidad humana. En diálogo con el semiólogo Yuri Lotman y el filósofo Michel Foucault, diremos que textos artísticos como las series de TV serán un terreno fértil para poner en cuestión cómo se reactivan hipotéticos instintos, en torno a una noción de "anomalía” y en relación con los complejos mecanismos que aseguran su domesticación y su control. Analizaremos la serie The Fall, narrativa donde la poliédrica construcción de un instinto en la figura ficcional del asesino serial no fluye de manera aislada, pues lo sexual comulga para conformar un complejo orden de lo instintual. En tal sentido, el relato captura la imposibilidad de plantear la problemática del instinto sin recalar en las identidades individuales y colectivas, como también en los regímenes que las sostienen. En función de ello, el instinto se desprendería parcialmente de su carácter biológico, deviniendo categoría semiótica de análisis: operatoria textual que permite atender a dominios cognoscitivos, al tiempo que pone de manifiesto aspectos éticos en una comprensión determinista de subjetividades sobre las cuales las culturas inscriben sus sentidos.
\end{abstract}

Palabras clave: series de TV | instintos | asesino serial | semiótica de la cultura | traducción

\section{Serial instincts}

\section{Abstract}

This article assumes that instinct proposes an expeditious solution for contemporary culture, homogenizing multiple manifestations from the protective intensity of the maternal and the irremissible loss of the sexual, to the unstoppable murderous yearning. Our hypothesis holds that this category is conformed as a "semiotic scaffolding" whose function would be to translate human irrationality. In dialogue with the semiologist Yuri Lotman and the philosopher Michel Foucault, we will say that artistic texts such as TV series will be a fertile ground for questioning how hypothetical instincts are reactivated, around a notion of "anomaly" and the complex mechanisms that ensure their domestication and control. We will analyze The Fall, narrative where the polyhedral construction of an instinct in the fictional figure of the serial killer does not flow in an isolated manner, since sexuality appears to conform a complex instinctual order. In this sense, the story captures that the problem of instinct recalls individual and collective identities, as well as regimes that sustain them. Based on this, instinct would be partially detached from its biological character, becoming semiotic category of analysis: textual operative that allows to attend to cognitive domains, and to show ethical aspects in a deterministic understanding of subjectivities on which each cultures inscribe meanings.

Key words: TV series | instincts | serial killers | cultural semiotics | translation

\section{Introducción}

No dudamos en afirmar que las series televisivas devienen prismas para observar las dinámicas de nuestra contemporaneidad. Su circulación masiva las define como máquinas culturales que traducen activamente la historia y las dinámicas sociales, a través de complejos procesos de percepción y construcción del mundo que atraviesan las fronteras geopolíticas. Basta observar cómo opera uno de los repositorios de narrativas más utilizados en la actualidad, el sitio de streaming Netflix. El raudo aumento de suscriptores, la creciente inclusión de ficciones internacionales y la variedad creativa de relatos propios hacen de esta cadena digital un terreno sumamente fértil para indagar cómo las nuevas formas de consumo modifican y trastocan las políticas estéticas de las series televisivas, en tanto formas artísticas de la actualidad.

\footnotetext{
arielgomezponce@gmail.com
} 
De manera ejemplar, un aspecto de interés para explorar esta lógica radica en el modo en que el sitio en cuestión organiza sus contenidos según organizaciones tipológicas que, en principio, reconoceríamos como géneros discursivos. Allí, "Mujeres que se apoderan de la pantalla", "arte sombrío" o "películas de impacto visual" aparecen en reemplazo de aquello que canónicamente consideraríamos como "drama", "gótico" o "policial”, quizá porque, como bien intuyó el filósofo Mikhail Bakhtin (1953[2008]: p. 247), el género responde a la pugna entre la permanencia y la innovación, siempre vinculada a cambios en la historia y, por ende, a cambios sociales.

Por lo demás, uno de estos géneros innovadores que Netflix ofrece ha dado en llamarse "instintos criminales”. Aparecerán, en esta inédita tipología, ficciones tales como: la serie que narra la vida de Pablo Escobar, Narcos (Netflix, 2015); la reversión estadounidense del relato danés The Killing (AMC, 2011-2014); la galardonada y laureada Breaking Bad(AMC, 2008-2013); el intrincado policial The Following (Fox, 2013-2015); $y$, entre muchas otras, la exitosa serie irlandesa (de gran audiencia y reconocida por la crítica) The Fall (RTÉ One, 2013-2016), sobre la cual nos detendremos en este artículo.

Pero, ¿qué tienen en común estas historias que Netflix agrupa bajo la improvisada nómina de un "instinto"? ¿Por qué un sitio de consumo internacional opta por ofrecerles a sus espectadores de todas partes del mundo, un conjunto de relatos que, por igual, se designa, genéricamente como "instintivos"? ¿Qué información guarda el término "instinto" que permite su reconocimiento y desciframiento en la recepción del mercado global?

En líneas generales, podríamos intuir que son todas series de TV que trabajan la incorporación del crimen en su mecánica instintiva, al tiempo que ponen en escena múltiples mecanismos para la normativización que la cultura lee como "anormales". Se trata de un supuesto que nos conducirá a revisar críticamente sus apariciones más actuales, propiciando una labor que nos lleva a problematizar cómo emerge el instinto como categoría cultural y masiva. La pregunta que surge y que orientará este estudio es qué sentidos guarda en su interior esta compleja noción que, en el espesor de la memoria, rememora la tenacidad humana por demarcar los límites con lo animal, al tiempo que despunta la deshumanización de un sinnúmero de alteridades.

Para dar cuenta de ello, el primer apartado de este trabajo estará dedicado a arrojar luz sobre la relación entre orden instintual y anormalidad. Como es sabido, el problema de la anomalía ocupa un lugar preponderante en la propuesta del filósofo Michel Foucault (2002 [2014]) y, por ello, sus aportes funcionarán como el puntapié inicial de nuestra reflexión. Señalamos que el recorrido propuesto no puede comprenderse si no es dentro de su proyecto orientado a explicitar las lógicas de formación y transformación del poder y el saber en la normalización social. En este contexto, la formación del concepto de "anormalidad" hacia finales del siglo XIX funciona como puerta de ingreso para la comprensión de instituciones del control y la vigilancia que intervienen en el diagnóstico de los sujetos, estelas de sentido que perdurarán durante los derroteros del siglo $\mathrm{XX}$.

Nos propondremos, entonces, indagar una de las hipótesis más arriesgadas del filósofo francés: "el instinto será, desde luego, el gran vector del problema de la anomalía" (2002, p. 128). Se trata, en otras palabras, de entender cómo el nacimiento de esta categoría permitió “justificar” todo un ámbito de objetos. Bajo este sistema de pensamiento, atenderemos cómo dicha noción traza una zona conflictiva, orientada a resolver interrogantes de larga data en la historia de la humanidad (ello es, la frontera entre lo humano y lo animal), pero también organizadora de todo un entramado que explica la existencia de alteridades. La propuesta foucaultiana del instinto como "grilla de inteligibilidad" nos permitirá comprender un instinto que adviene como un difuso “andamiaje" explicativo, entre pulsión e impulso, hábito y herencia, y naturaleza y la cultura.

Viene al caso señalar que, aún conscientes de que la psicología, la neurología y los estudios de la cognición han dedicado ríos de tinta al estudio del instinto, nuestro propósito se orienta a desmontar convenciones históricas, descubrir las marcas ideológicas y desnaturalizar aquello que aparece como natural en el uso reglado de esta categoría. Dicho de otro modo, implica evaluar cómo el lenguaje y sus modos de nombrar y distribuir, registran las singularidades, las excepciones y las contradicciones de lo humano. De lo que se trata, entonces, es de revisar dos hechos fundamentales que atraviesan toda indagación documental en sede semiológica: qué significa y cómo significa este problema insistente que oscila lo biológico y lo cultural.

Por ello, en un segundo momento, recuperaremos la noción de traducción perteneciente a la semiótica de Yuri Lotman. Este estatuto teórico nos brindará herramientas oportunas para el estudio de cómo las series de 
TV, en tanto textos artísticos, captan las modulaciones instintivas, traduciendo parcelas informacionales que, divulgadas por los discursos de las ciencias, conforman todo un imaginario cultural sobre el instinto. Aplicaremos estas reflexiones a una de sus derivas más recientes: su inclusión en la representación ficcional del asesino serial. Se trata de un recorrido que no estará abocado a una historia del asesino, sino más bien a fijar pautas que colaboren con una genealogía desde su nacimiento como figura cultural y masiva.

El apartado final estará dedicado a trasladar estas indagaciones y el carácter expansivo de estos interrogantes a una serie como The Fall. La narrativa dejará entrever que la poliédrica construcción de un instinto asesino no fluye de manera aislada, pues lo sexual comulga para conformar un complejo orden metafórico de lo instintual. En un relato que hace de la suspensión de fronteras su conflicto central, el instinto aparece como solución expeditiva que llenará un "vacío" de sentido, traduciendo un amplio conjunto de prácticas perversas, pero también de aquellas sexuales. En tal sentido, la serie funcionará como una "instantánea" que captura momentos precisos del proceso cultural, arrostrando la imposibilidad de plantear la problemática del instinto sin recalar finalmente en el tema de las identidades culturales individuales y colectivas, como también en los regímenes que las sostienen.

\section{Sobre la dinámica de los instintos: breve genealogía}

Quisiéramos comenzar este apartado, recuperando un desplazamiento crucial en la historia criminológica: el tratamiento de situaciones donde crimen y locura pierden la nitidez de sus formas, y que Michel Foucault (2002) define en el marco de una monstruosidad moral. ${ }^{1}$ Se hace necesario, entonces, sintetizar las reflexiones que el filósofo emprende sobre un conjunto de pericias psiquiátricas que la justicia solicita en una serie de casos pronunciados en 1826, y que escenifican cómo "del acto sin razón se pasa al acto instintivo” (p. 127). Ellas funcionan como ejemplos paradigmáticos que permiten entender las condiciones de posibilidad que, en sintonía con los objetivos del filósofo, explican el uso reglado de una noción como el instinto en el terreno de la interdiscursividad social. De lo que se trata, por ende, es de evaluar cómo la noción del instinto (que Foucault no duda en afirmar que supone una pieza fundamental en la tensión del poder/saber) interviene, inaugurando recorridos explicativos para volver punibles los actos más perversos del ser humano.

En este contexto, Foucault se preocupa por explicar cómo, en los albores del siglo XIX, la psiquiatría aparece en el campo jurídico para colaborar con la explicación de los crímenes más irracionales, indefinibles, sanguinarios y violentos que suponían el movimiento de un deseo irresistible y del propio delirio del sujeto. Basta recordar el caso que, de manera ejemplar, toma como disparador de sus reflexiones: "la mujer de Sélestat", aquella criminal que sin motivo explícito mata a su hija, le corta una pierna y la devora. El asesinato en cuestión le permite estudiar el desarrollo de las operaciones que buscan "enmascarar" la ausencia de razón y "volver inteligibles" un amplio caudal de crímenes sin aparente motivación (p. 132). Porque aquí la problemática principal recae en la imposibilidad de catalogar el acto y en el intento insistente por parte de los argumentos esgrimidos que buscaban probar cómo el accionar de la mujer estaba impulsado por el hambre y, por ende, por la supervivencia.

Aparecerá allí un objeto totalmente nuevo que deviene "marca constitutiva" de la locura y las pasiones, pero que emergerá además como calificativo de impulsos, pulsiones, automatismos y tendencias de lo humano. En todos los casos, referimos a expresiones que son, según lo afirma el filósofo, "designaciones, toda una serie de nombres, términos, adjetivos, etcétera, que designan la dinámica de lo irresistible (...): el instinto" (p. 126). Por ello, las formas de las pasiones exacerbadas y el furor humano, de los accionares en la frontera de lo irracional, ingresan indiscriminadamente dentro del "delirio instintivo" de la mano de una criminología incipiente que buscaba arrojar luz a los rincones más inexplicables de la conducta humana y a todo un haz de sujetos anormales (criminales, violadores, perversos, etc.). De allí en más, y como bien supone el antropólogo Roger Bartra (2013), el instinto supondrá “una excusa para cualquier comportamiento inmoral, pues siempre es posible decir que la falta no la comete conscientemente el individuo, sino que viene de algún proceso mecánico incontrolable, de alguna causa genética o desequilibrio bioquímico” (p. 36).

Por lo demás, vale señalar que, "como grilla de inteligibilidad” (Foucault, 2002, p. 131), el instinto no permanecerá recluido en campos como la psiquiatría y la criminología, pues esta categoría cartografiará una larga tradición en la cultura occidental. Basta recordar cómo, además de propiciar una revolución científica, la 
propuesta de Charles Darwin [1809-1882] inauguró un paradigma de pensamiento que tomó al instinto como su instancia de debate. Es sabido que las relecturas de la teoría darwiniana consolidaron un imaginario cuyo dogma cita que todas las especies buscan ascender a un estado máximo de optimización, pues la evolución significaría progreso y en la competencia recaería su lógica primordial. Para todo un modelo científico-cultural que, en investigaciones previas (Gómez Ponce, 2017), reconocimos como un darwinismo canónico. ${ }^{2}$ Las estrategias que sostienen la "lucha por la vida" estarían inscriptas en la biología de los seres porque, en ellos, existiría algo mecánico e innato que se ha dado en llamar "instinto".

Por ello, Foucault (2002) entenderá que la dinámica los instintos cobró protagonismo en otros órdenes discursivos gracias a una "inyección de la ideología evolucionista” (p.129). De ello da cuenta aquella antropología que, en los derroteros del siglo XX, asumió que recuperar esta matriz evolutiva del animal era también arrojar luz sobre la estructura atávica de la humanidad. ${ }^{3}$ Dicho de otra manera, comprender cómo funcionaba el instinto resultaba esencial para explicitar fenómenos que yacen en nuestra estructura somática como "rudimentos" que aún nos seguirían condicionando. De lo que se trató es de un intento científico por responder un amplio caudal de interrogantes: " $\mathrm{el}$ instinto del hombre es el instinto del animal? ¿El instinto mórbido del hombre es la repetición del instinto animal? ¿El instinto anormal del hombre es la repetición de instintos arcaicos del hombre?" (Foucault, 2002, p. 129).

Aun a riesgo de simplificar, a esta complejidad habría que agregar una serie de confusiones y trivializaciones teóricas que también hicieron del instinto una suerte de comodín científico. Valgan de ejemplos el límite poco claro entre instinto/hábito y aprendizaje en la sociobiología, la traducción inexacta de la pulsión freudiana (Triebe), ${ }^{4}$ y la insistencia de la psicología heredera del conductismo por trazar una "biología de la emoción" humana mediante la búsqueda de determinados "residuos" biológicos en nuestra especie.

De modo que, entre pulsión e impulso, hábito y herencia, e inconsciente y consciente, el instinto aparece como un difuso y precario principio explicativo que reflexiona tanto sobre lo humano como lo animal. Y, al tiempo que rememora la tenacidad humana por demarcar los límites con la naturaleza, el instinto despunta la deshumanización de un sinnúmero de alteridades, acaso determinadas por los discursos de las ciencias, pero también fuertemente vehiculizada desde el centro de los pensamientos cotidianos. Por tanto, decimos que el instinto como principio explicativo ha permitido "justificar" todo un ámbito de objetos y, quizá por ello, en las dos primeras décadas del siglo XX y consecuencia de estos debates, más de 400 autores escribieron artículos y libros dedicados a los mecanismo instintuales, problematizando en total más de 6 mil clases de instintos (Blumberg, 2005, p. 16).

En conjunto, estos órdenes científicos contribuyen a la formación de una economía de los instintos que, descubierta en el siglo XIX, continuó iluminando los discursos del siguiente siglo e incluso la actual lectura de toda una constelación de anormalidades que parecen provenir de las dinámicas más atávicas e irracionales de lo humano. De allí en más, y siguiendo a Foucault, podemos sintetizar que:

A partir de la noción de instinto, y en torno de lo que otrora era el problema de la locura, podrá organizarse toda la problemática de lo anormal, lo anormal en el nivel de las conductas más elementales y cotidianas. Ese pasaje minúsculo, la gran deriva que el monstruo, el gran monstruo antropófago de principios del siglo XIX, resulte amonedado, en definitiva, en la forma de todos los pequeños monstruos perversos, solo pudo darse gracias a la noción de instinto y la utilización y el funcionamiento de este en el saber. (Foucault, 2002, p. 128)

\section{El instinto asesino como traducción cultural}

La pregunta que surge, entonces, es cómo trasladar las reflexiones foucaultianas al modo en que la cultura re-presenta los instintos. $\mathrm{Y}$, en tal sentido, la semiótica de la cultura fundada por Yuri Lotman (1990) puede intervenir, volviendo inteligibles los modos en que los textos del arte, su objeto analítico privilegiado, "traducen" caudales de información.

Lo primero a señalar es que la propuesta de Lotman (1978, [1998]) define la traducción como un mecanismo semiótico de frontera que implica "el sentido de un mecanismo buffer que transforma la información de un peculiar bloque de traducción” (p. 27). Se trata de una lectura superadora de la traducción que colabora con el estudio de los textos como fragmentos de un orden cultural que incansablemente buscan dialogar entre sí, aun cuando los lenguajes que manejen sean diferentes. Porque, según Lotman, allí donde la cultura no pudo o no supo cómo traducir a sus lenguajes ciertos fenómenos, 
se produce una "mancha de sentido" y el acto creativo ocupa un lugar de frontera y de traducción "inexacta”, pero siempre productiva.

Desde este punto de vista, el instinto se constituye como un mecanismo de traducción inexacta: en otras palabras, referimos a una operatoria fronteriza que le permite al instinto resolver cierta "vacancia de sentido", como una solución expeditiva al modo en que los sistemas culturales tratan con los comportamientos “anormales". Ello puede observarse en el modo en que esta categoría adscribe, fuertemente, a subjetividades asentadas en una base instintiva que parecería inmodificable por ser biológica, homogeneizando así múltiples manifestaciones que van desde la intensidad protectora de lo maternal y la perdición irremisible de lo sexual, hasta el irrefrenable anhelo asesino, sobre el cual nos detendremos seguidamente.

Por este motivo, nuestra hipótesis sostiene que los instintos se conforman como un "andamiaje semiótico" (Hoffmeyer, 2011, p. 62): un rótulo metafórico cuya función sería la de resolver (traducir) la irracionalidad humana, dejando de lado toda inscripción sociogénica y justificando procesos incontrolables o hipotéticos desequilibrios genéticos que se hallarían en la mecánica biológica del sujeto. Desde esta perspectiva, el instinto se desprende parcialmente de su carácter biológico, deviniendo categoría semiótica de análisis: operatoria textual que permite atender a dominios cognoscitivos, al tiempo que regula aspectos éticos y morales en una comprensión determinista de subjetividades sobre las cuales las culturas inscriben sus sentidos.

En diálogo con Lotman, entendemos que los textos artísticos y sus modos de subjetivación ficcional serán un terreno sumamente fértil para poner en cuestión esta hipótesis. Por ello, proponemos atender a determinados personajes que reactivan esta lectura de hipotéticos instintos, al tiempo que ponen en escena complejos mecanismos para domesticarlos o bloquearlos. Es, en tal sentido, que los aportes Michel Foucault (2002) se vuelven pertinentes, puesto que para el filósofo lo instintivo se halla relacionado con la escenificación de redes de poder y con los límites de una tecnología de la racionalidad en una sociedad disciplinaria que persigue la "higiene del cuerpo social" (p. 114).

Ahora bien, un ejemplo pertinente para reflexionar sobre esto yace en la figura del asesino serial. Hay, no obstante, algo ininteligible en el devenir asesino que respondería, en términos del semiólogo ruso, a una "mancha de sentido" que la cultura busca incasable- mente reponer, pues su accionar despuntaría siempre la desmesura de una violencia ininteligible. Sin embargo, se hace necesario señalar que, a través de la historia, el acto de matar ha sido traducido de maneras diferentes, vinculadas ellas al sistema de valores y los modelos morales que cada cultura conjura.

Por ello, en tanto los asesinatos estarían presentes desde la noche de los tiempos, nuestra lectura opta por un recorte histórico situado a partir de una de sus manifestaciones: el asesino serial, figura que, en los derroteros de las últimas décadas, se emplaza en el centro de la escena. Y aunque la diacronía nos ha legado ejemplos notables como el noble Gilles de Rais [1405-1440], la condesa y presunta vampiresa Erzébet Báthory [15601614] o el enigmático Jack The Ripper, Jorge Bafico (2014) entiende que la serialidad sufre una emergencia explosiva a partir de los '70, periodo en el cual los medios inauguran la circulación global de la información. Basta recordar "celebridades" como Edmund Kemper ("El ogro de Santa Cruz", culpado de asesinar estudiantes universitarias), Ted Bundy ("El asesino de señoritas”, a quien se le adjudican más de cien crímenes), y, en sede local, Cayetano Santos Godico ("El petiso orejudo", asesino más joven de la historia argentina), paradigmas ellos de este paso "desde el anonimato a la notoriedad pública, más allá de que esta se continúe irremediablemente con la cárcel” (Besuchio, 2014, p. 9).

Interesa destacar que ello resulta coincidente con un caudal de asesinatos que comienzan a profesarse y sobre los cuales la policía no podía explicitar móvil o perfil. Homicidios pasionales, ajustes de cuentas o enfrentamientos entre pandillas eran crímenes cuya motivación podía ser determinada casi con facilidad, pero la serialidad ejercía otra lógica difícil de captar, en tanto implicaba un comportamiento que quizá asentaba sus raíces en la infancia del criminal: problemas de adaptación social, abuso infantil, inmadurez psicológica y falta de contención por instituciones familiares y educacionales, entre otros, aparecían como terrenos áridos que debían ser investigados con el objeto de delimitar la figura del asesino serial.

De hecho, en este periodo, el agente Robert Ressler acuñará el término "asesino serial”, introduciendo ciertos patrones ritualísticos que evidencian una clara naturalización de la conducta homicida: marcado por la "evidencia de un impulso" (o, más bien, por su falta de inhibición), el serial killer se caracteriza por un ciclo de furor que es, sin embargo, metódico y progresivo, pues su proceder "evolucionaría" mediante el perfeccionamien- 
to (Cfr. Ressler et al, 2005, p. 296). Además de proponer un método para la detección y comprensión de esta tipología de criminales, Ressler colaborará también en la creación de la Unidad de Ciencias del Comportamiento del FBI en un país como los Estados Unidos que, según las estadísticas, posee el $65 \%$ de los asesinos mundiales.

Con todo, no podemos menos que pensar la creación de este departamento (que, además, será ficcionalizado infinitas veces) como corolario de un proceso que viene concretizándose en los últimos dos siglos. Como intuye Foucault, cuando la psiquiatría y la medicina hacen del asesinato un objeto de estudio, el asesino emerge como un sujeto a corregir "en la medida en que la familia y las instituciones, con sus reglas y sus métodos, han fallado" (p. 56). Y, por tanto remite a una figura anormal, resulta necesario que la sociedad de la norma busque presuntos factores comunes para marcar y controlar el devenir de estos sujetos.

Viene al caso señalar que, en este contexto, apareció aquel instinto recientemente debatido (y, también, distorsionado) por la etología, la psicología y la antropología, como un lugar privilegiado para explicitar toda una gama de comportamientos de inasequible comprensión. Junto a Foucault, diríamos que, de la mano del FBI, la criminología intentó traducir esta "anomalía como desorden del instinto" (p. 208), abriendo con ello cuantiosos interrogantes en torno a estos "monstruos morales": ¿ son ellos producto de un condicionamiento social y de un contexto de interacción? ¿ $\mathrm{O}$, más bien, de factores biológicos, como una predisposición genética que impulsa al crimen?

A nuestro entender, este sucinto recorrido pone de manifiesto una compleja figura propia de nuestra épo$\mathrm{ca}$, que puede ser reflexionada mediante el modo en que traduce un comportamiento "anormal". Y, al realizar una genealogía por el modo en que la cultura reproduce esta lógica, emergen cuantiosos ejemplos que replican la idea de un "instinto asesino". Se trata, en todos los casos, de sujetos que, despreciados por su proceder, adquieren sin embargo popularidad. De ello clara cuenta ese exitoso continuum cinematográfico que va desde el reconocido caníbal de The Silence of The Lambs (Demme, 1991), pasando por un Brad Pitt a la caza de un asesino que traza sus crímenes bajo la simbología de los pecados capitales en Se7en (Fincher, 1995) o el psicópata multimillonario y sádico de American Psycho (Marron, 2000), hasta llegar a las sagas sanguinarias como The Texas Chain Saw Massacre iniciada en 1974 o los cruentos filmes Saw (2004-2010).
Pero, también, los ejemplos en la pantalla pequeña serán profusos. En esta lógica, la serie Dexter (Showtime, 2006-2012) pareciera ser el máximo exponente, exhibiendo la historia de un asesino serial camuflado en el núcleo mismo de una sociedad estadounidense "normal" y bajo la coartada de un modelo canónico de familia. De allí en más, algunas series televisivas también innovarán en la creación de nuevas figuras, como es el caso de la aclamada True Detective (2015) que entrelaza crimen a un intenso bagaje filosófico. Otras, por su parte, optan por recurrir a estrategias intertextuales, como sucede en Bates Motel (Universal, 2013-2017), que narra los inicios del particular psicópata y su tortuosa relación maternal que inaugurara Psycho (1964), o bien Scream(MTV, 2015) y Hannibal (NBC, 2013-215) que releen los asesinos seriales protagonistas de los filmes homónimos de los años '90.

Hay, asimismo, series que ficcionalizan grandes hitos en la historia del crimen. Por ello, la quinta temporada de American Horror Story (Fox, 2005) recreará la casta de los más sádicos asesinos (como Richard Ramírez, Aileen Wuornos o Jeffrey Dahmer) quienes regresan del más allá para buscar nuevas víctimas. $\mathrm{O}$ bien su más reciente correlato, American Crime Story (FX, 2017), antología que se ha preocupado por contar reconocidos crímenes, como el juicio a O.J. Simpson o el asesinato del modisto Gianni Versace. Ocupan un lugar importante, además, la reciente Manbunt: Unabomber (Discovery, 2017), que relata la cacería de "Ted" Kaczynski, terrorista interno que azotó a la comunidad con cartas bomba durante dos décadas; y Mindhunter (Netflix, 2017), serie que, casualmente, narra la historia de dos agentes del FBI que comienzan a organizar los perfiles psicológicos de los asesinos, en clara representación de aquel momento histórico al que aludimos líneas arriba.

Vale recordar, no obstante, que estas serialidades (que, como bien aludimos, Netflix engloba bajo el género "instintos") pertenecen a la maquinaria creativa estadounidense $y$, por este motivo, presentan iterativamente aquello que llamaríamos un "american way of murder”. El interrogante que emerge, entonces, es qué alcance tiene la industria de contenidos estadounidense (referente hoy ineludible en el orden masivo) en los recorridos narrativos que trazan serialidades de otras geopolíticas. Por ello, este trabajo estará abocado a estudiar la existencia cultural de un "instinto asesino" fuera del prisma audiovisual estadounidense. $Y$, en tal sentido, la reciente serie europea The Fall se presenta 
como un terreno sumamente fértil para explorar esta cuestión.

\section{The Fall y los instintos en tensión}

Creada por Allan Cubbit, The Fall es una serie anglo-norirlandesa emitida entre 2013 y 2016 por la cadena RTÉ One. Compuesta por tres temporadas de alrededor de cinco episodios cada una, propone un policial detectivesco ubicado en Belfast, Irlanda del Norte. En líneas generales, la trama siendo singular, suena a la vez familiar, pues ella se centra en Paul Spector (Jamie Dornan) quien, desde el comienzo y a diferencia de otros relatos del género en donde todo devela paulatinamente, se expone como un asesino serial. Por ello, a través de su nombre, la serie experimenta una “caída” que evoca el núcleo de la historia: ello es, una metáfora no solo del quiebre moral en el protagonista, sino además de la misma lógica compositiva de esta narrativa orientada a mostrar la captura y el ocaso de un asesino serial.

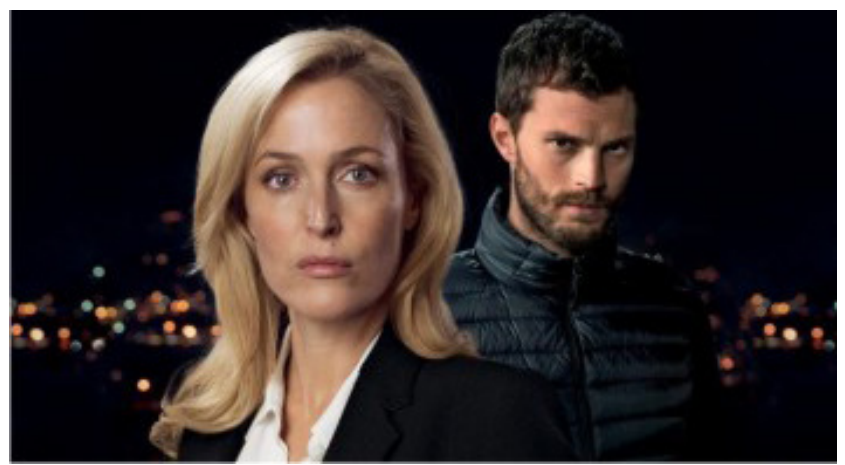

Imagen 1. Captura de pantalla del género serial, definido por Netflix como "instintos criminales". En su interior, la imagen promocional de la serie The Fall.

The Fall se centra, entonces, en un proceso de (re) conocimiento del asesino desde una mirada bifocal, tanto desde la introspección que realiza el mismo criminal, como también de la visión que ofrece su cazadora, la detective Stella Gibson (Gillian Anderson). Expuesto desde el comienzo el culpable y revelado el misterio, todo remite, en consecuencia, a comprender en detalle quién es Paul Spector. Ello se sostiene, asimismo, en un relato que opta por no exponer la desmesura de la sangre, escaseando en escenas de asesinatos y preocupándose más por exhibir la interioridad de estos dos protagonistas que estarán en fricción a lo largo de la serie.
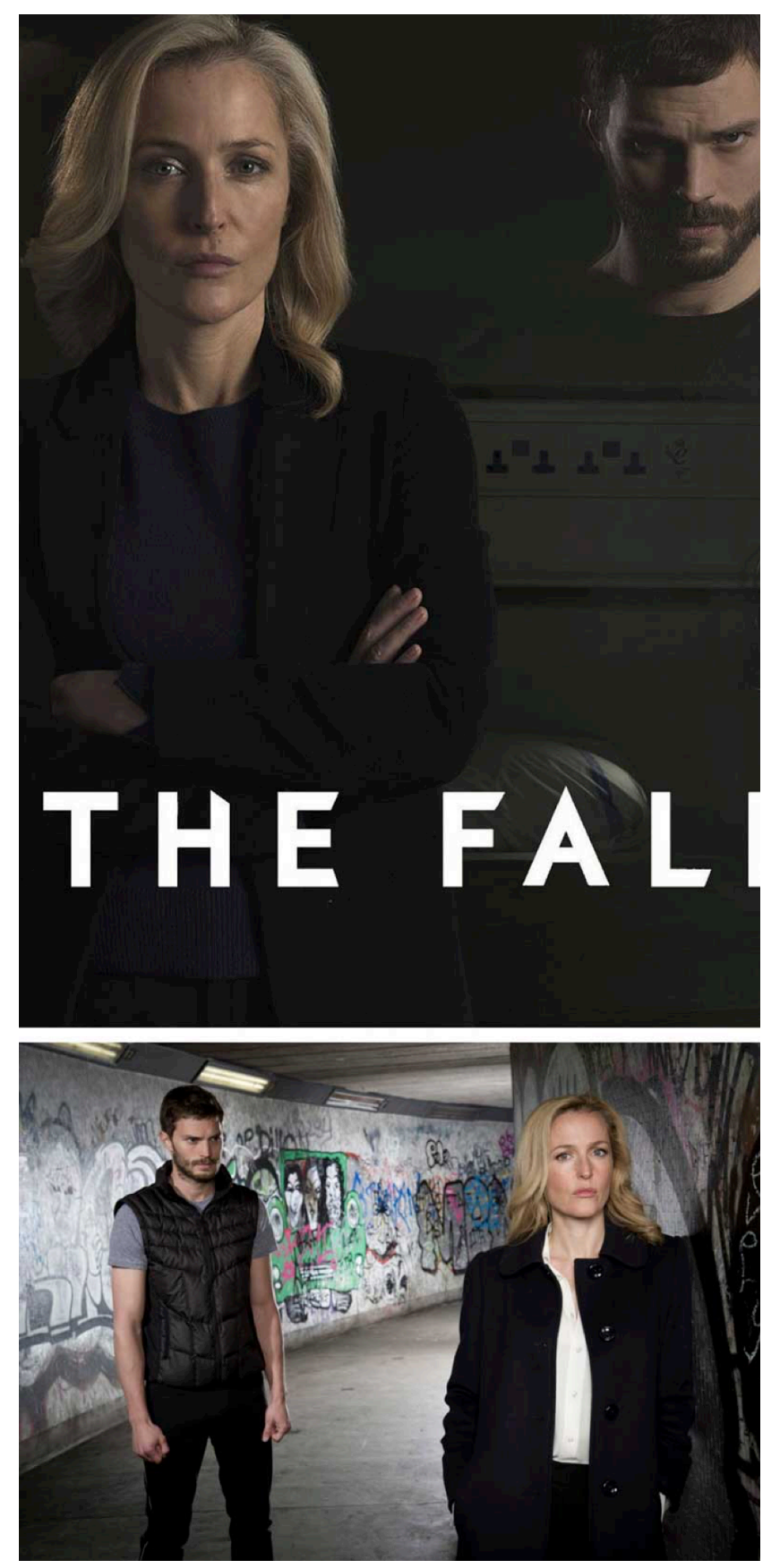

Imagen 2. Póster e imagen promocional de la serie The Fall. Cubitt, A.; Verbruggen, J. (2013). Reino Unido: BBC Northern Ireland.

Interesa, de manera especial, el modo en que se inaugura The Fall. Se trata de un diálogo entre dos colegas en un bar. Allí, una de los interlocutores (quien, como sabremos luego, será la siguiente víctima de Spector), dirá que:

Sarah Kay: la mayor parte de lo que llamamos necesidades son deseos. Necesitamos aire para respirar, agua, calor, alimento para comer. El resto, amor, aprobación, reconocimiento, alabanza o lo que sea, son deseos. 
Kevin: Entonces, ¿qué es el sexo? ¿Una necesidad o un deseo?

Sarah Kay: Ambos, si lo hacés bien. (101)

Intercalado a este diálogo, la serie introduce a Spector, vestido con ropa deportiva negra y encapuchado, ingresando a la habitación de un domicilio que acaba de allanar. En el lugar, se quitará la máscara, se mirará ante el espejo y comenzará a tomarse fotografías en el baño, mientras huele la ropa interior de Sarah. Adviene, más tarde, un gesto que puede tomarnos desprevenidos: desnudarse por completo, exhibir su cuerpo tonificado y ejercitarlo en lo que, minutos después, devendrá una escena del crimen.

La pugna entre "deseo" y "necesidad", aquellos dos lugares comunes en los que cae la categoría que nos convoca en este trabajo, introduce una constelación semántica para dar cuenta de prácticas que, densamente, se describirán como instintivas en los derroteros del seriado. No obstante, bien puede observarse que el instinto asesino parece no fluir de manera asilada, pues lo sexual comulga con él para conformar un complejo orden metafórico de lo instintual. De lo que se trata, entonces, es de asumir que este primer diálogo presenta al instinto como una poliédrica categoría que pierde la nitidez sus límites, y sobre este problema limítrofe rondará toda la trama. En función de ello, hablamos de una serie que hace de la suspensión de fronteras su conflicto central. Observemos esto en más detalle.

En un nivel superficial, esta problemática fronteriza se introduce a partir del poema que bautiza al relato, "Los hombres vacíos" (1925) de T.S. Eliot: "entre la idea y la realidad / entre el movimiento y el acto / cae la sombra" (103). Este complejo linde entre lo real y la fantasía inaugurará un amplio caudal de límites sobre los cuales el instinto cobrará vida como andamiaje explicativo del motor de arranque de las acciones de Spector: hablamos, en otras palabras, de un personaje que aparece constantemente determinado por aquello que "los instintos están diciendo" (206). Incluso, emergen otros términos que ingresan dentro del campo sinonímico del instinto en la lengua inglesa (urge, drive, dessire, gift, compulsion, inclination, need, etc.). Dicho de otro modo, ante el interrogante de qué moviliza al protagonista, se opta por la solución expeditiva de todo un orden instintual que, efectivamente, llena un "vacío" de sentido, traduciendo un amplio conjunto de prácticas sexuales y perversas.

Con todo, las claves de esta traducción hay que buscarlas en el modo en que The Fall representa la fi- gura del asesino. Primero, diríamos que Spector se caracteriza a partir de aquel instinto de ritmo ritualístico que subyace en todo depredador, por tanto emprende el mismo recorrido de gestos en cada crimen: luego de acechar, estudiar y abordar en su domicilio a las víctimas (dejando pruebas de su presencia, en un intento por volverlas vulnerables), las ataca desprevenidamente, las ata con su ropa interior, las asfixia, las desnuda, las baña y pinta sus uñas, y finalmente toma fotografías del hecho. Intervendrán, en este punto, las estrategias de caza que le sirven a Spector para interactuar con sus presas, pues todo contacto se realiza por las vías de la atracción.

Consciente de una belleza que aparece como "cebo", él se acerca a las víctimas, las hace sentir seguras y las corrompe. Se trata de mujeres que, de alguna manera, se dejan inocular por lo simbólico del acto de la posesión, desconociendo que este sujeto las objetivará en su sentido más literal, dado que "las usa como muñecas" (103). También, es una seducción que penetra en el orden masculino, y en estos oficiales de la policía que creen ver “algo fascinante en él. Una extraña atracción” (206). Así, la operatoria de Spector yace, en términos de Julia Kristeva, en un poder de la perversión: en la captación de los sujetos femeninos, pero además en la identificación de los restantes hombres, dando lugar a la ambivalente idea de "seducción masculina" trazada por el mito de Don Juan (Kristeva, 2001, p. 171).

Vale destacar que The Fall es una serie que se esmera en representar un imaginario basado en la idea de que "hasta un asesino serial puede tener una cara bonita" (105). Basta recordar el principio de la narrativa que relatamos líneas arriba (101), e incluso la captura de Spector (205): en los momentos previos a su ingreso a la celda, los oficiales lo desnudan, mientras el ojo de la cámara aborda detalladamente fragmentos de su musculatura. Por lo demás, el retrato desnudo y el cuerpo tonificado son acompañados por la extensión temporal de las escenas, todas ellas despojadas de banda sonora, intento por convocar la atención completa del espectador. Diremos, entonces, que la puesta en escena del asesino deviene confuso espectáculo: ello es, objeto a ser contemplado y visión de belleza, como una suerte de "señuelo" que intenta distraernos de la ausencia moral del protagonista, o bien rememorarnos que, en nuestra cultura contemporánea, aún sigue en vigencia

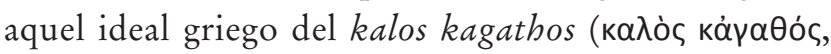
lo bello y lo bueno: una connotación física y estética que iría siempre de la mano de la virtud ética). 

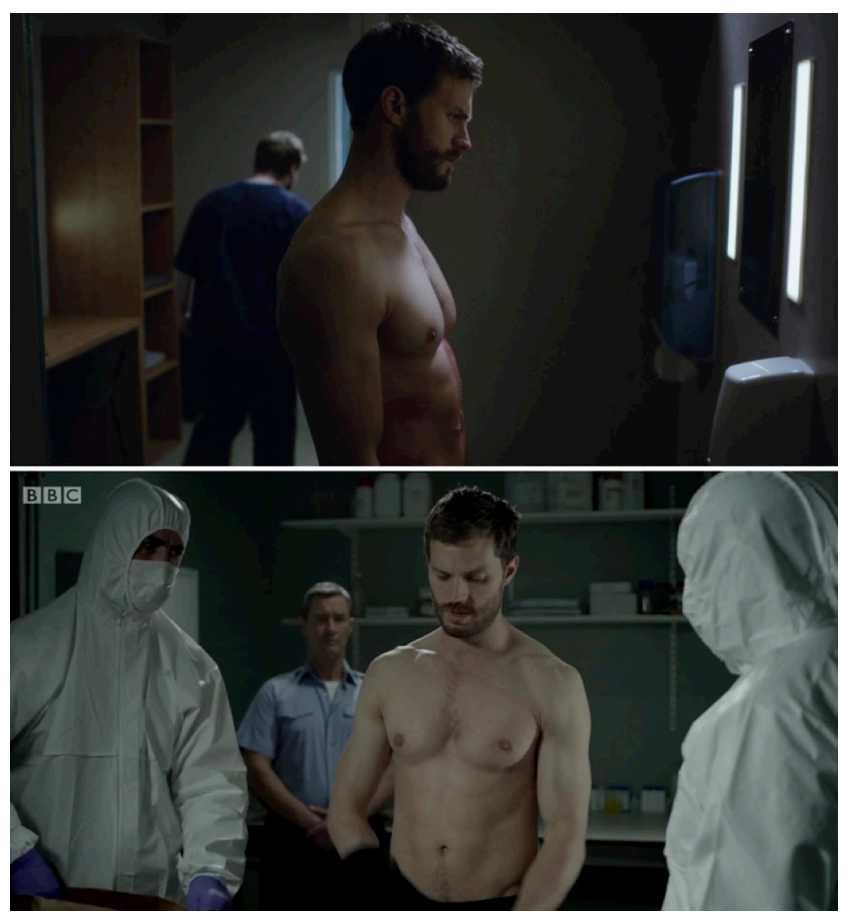

Imagen 3. Capturas de pantalla de los desnudos del asesino serial, Paul Spector (Jamie Dornan), en los momentos previos a su captura. Cubitt, A.; Verbruggen, J. (2013) The Fall. Reino Unido: BBC Northern Ireland.

En segundo lugar, interesa la fricción entre instinto asesino y fachada de "normalidad". The Fall narra un criminal que oculta su verdadera identidad bajo la apariencia del esposo ideal y padre devoto de dos pequeños hijos, Olivia y Liam. Spector trabaja, además, como un eficiente consejero de duelo y colabora regularmente con una línea de atención al suicida. Todo ello conforma aquel camuflaje perfecto del que seguidamente se sirven los asesinos seriales en las ficciones: un modelo de familia "normal" y de "buen" ciudadano, contextos que ayudan a pasar desapercibido dentro del orden social. Se trata, también, de una coartada que le permite mantenerse a resguardo de la Policía de Belfast, cuerpo policial que resulta incompetente, repleto de errores y falta de profesionalismo, e incluso carente de recursos humanos.

No obstante, la serie nos advierte de que el entorno familiar, como sistema normalizador, muestra sus fisuras. Ello sucede consecuencia de los trofeos que Spector acapara: fragmentos del cabello que guardará en un diario íntimo, repleto de imágenes de las mujeres asesinadas y de reflexiones que escribe. Casualmente, en estas memorias yace la carga sexual de su comportamiento, ya que son "su propia pornografía" (103) y son funcionales para excitarse y masturbarse fuera del crimen. El problema es que será en el resguardo de su hogar (en un desván que se encuentra sobre el dormitorio de su hija), en donde resida esta suerte de repositorio criminal que contiene no solo las memorias, sino además un maniquí vestido con ropa interior femenina que luego él mismo viste para tomarse fotos. Por lo cual, la perversión se cuela en el orden de la intimidad del asesino, ingresando en el núcleo mismo de este camuflaje de cotidianeidad perfecta que ha construido.

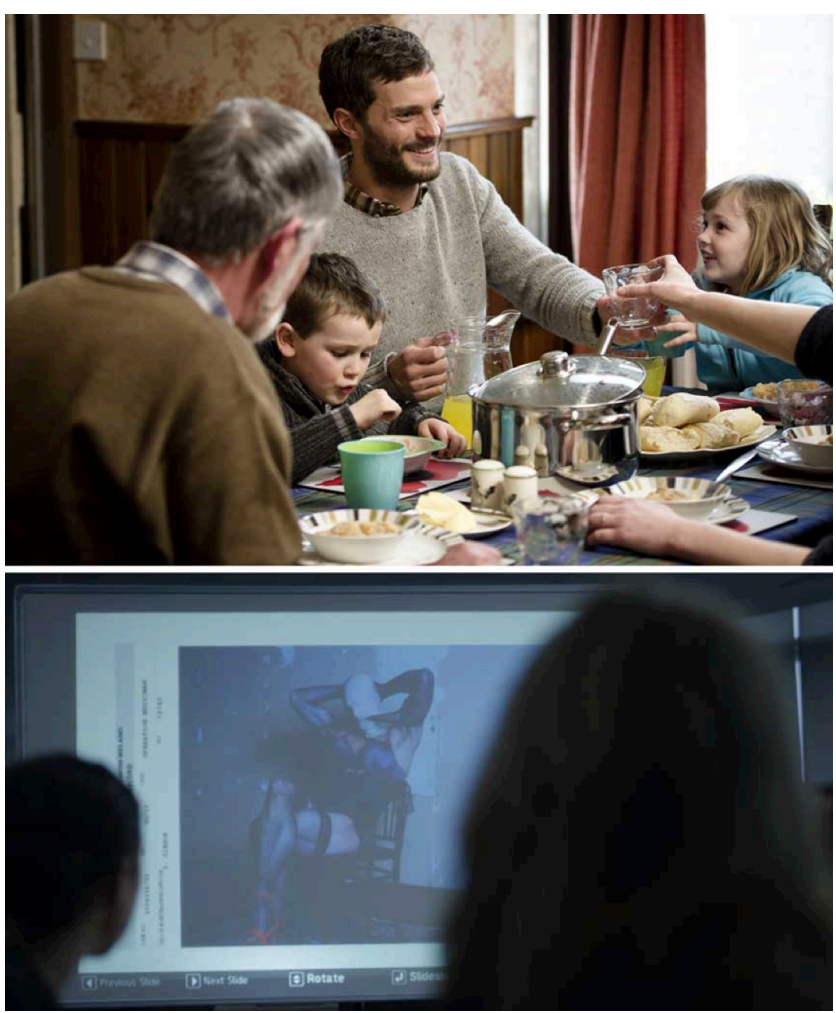

Imagen 4. Arriba: imagen promocional de Paul Spector (Jamie Dornan) junto a su familia. Abajo: captura de pantalla del asesino, vestido con ropa interior de sus víctimas y fotografiándose, mostrando con ello un escenario contrapuesto al familiar. Cubitt, A.; Verbruggen, J. (2013) The Fall. Reino Unido: BBC Northern Ireland.

Asimismo, en este contexto, importa cómo interviene nuevamente la metáfora del "vacío". Porque, casi al finalizar el seriado, Spector especificará que "solía pensar que había un bueco negro dentro de mí y que nada podría llenarlo. Entonces, tuve a mi hija” (306). De modo que, en su devenir asesino, la descendencia aparece como una línea de fuga, manifiesta en un devoto cariño hacia Olivia, ese pequeña hija (que, no obstante, se ve afecta por los crímenes del padre y lo está representando en pesadillas: sueña con una chica desnuda que dice haber visto en el techo, allí donde casualmente se esconden el maniquí y los trofeos). Se escenifica aquí otra confusa contraposición: un choque entre un hipotético instinto que lo moviliza 
y cierto sesgo moral en este asesino que reconoce sentir una fuerte afección por los niños. Y, por ello, Spector arrancará de su diario los recuerdos de Sarah Kay (sobre quien luego sabrá que estaba en cinta al momento del asesinato) e incluso escribirá una carta a su padre, diciendo que "nunca la habría matado si hubiese sabido que estaba embarazada. Los bebés son inocentes. Y yo siempre me sentí muy protector con los niños" (104). ${ }^{6}$

Sin pretender agotar los sentidos que guarda este complejo personaje, los rasgos señalados sirven como panorama para introducir la multiplicidad de fronteras que The Fall conjura. En el encuentro de estos variados polos y en el "vacío" que entre ellos se gesta, se inmiscuye un fuerte campo metafórico de un instinto asesino/depredador que bucea por los derroteros del relato. Diremos, por lo tanto, que lo instintivo viene a explicar conductas que la serie hace emerger a medio camino entre lo pulsional y lo biológico, o desde un nivel profundo que marcaría una incisión instintiva y que estaría "en lo profundo de su naturaleza” (206). Allí, cobran vida las prácticas de la desmesura, del furor irracional y del frenesí asesino que Spector entiende como un "perderse" (“lose yourself”), un “interruptor que se activó, una línea que se cruzó” (205).

Y viene al caso recordar que esta lectura de una "naturaleza instintiva” responde a la clásica comprensión etológica de Konrad Lorenz, quien asumió al instinto desde un "modelo hidráulico": es decir, como "sustancia en un recipiente" que energiza los comportamientos y libera una acción, a la forma de un gas que bombea y, eventualmente, estalla (Fromm, 1975, p. 30). En términos del semiólogo Nicolás Rosa (2006), referiríamos también a la representación ficcional de un "sistema de sometimiento instintivo": un sujeto humano que se enfrenta a la idea del deseo como instinto que busca vías de escape, y que "trata de modificarlo, de sustituirlo, de sublimarlo", en el intento por ocultarlo "detrás de la máscara de educación” (p. 207). De manera especial, ello puede atenderse en la confesión de Spector:

Los sentimientos, los pensamientos que yo experimento están más allá de lo que vos llamas fantasías. Los sonidos y los colores son más vívidos. Los olores son más intensos. Mi piel se vuelve más sensible a la más ligera de las presiones. El mundo exterior no significa nada, solo el mundo interior es real. Y es totalmente irresistible, compulsivo. Nada puede alejarte del borde. Ninguna ley o amenaza de castigo, moralidad, religión, miedo a la muerte. Todas esas cosas no significan nada comparado con la vida que estás a punto de extinguir (206).
En tal sentido y en comparación con otros seriados que abordan esta figura cultural, The Fall no innova en cuanto al registro utilizado para explicar el asesino. $\mathrm{O}$ eso, al menos, en lo que refiere al modo en que el protagonista pone en lenguaje su propio devenir.

La diferencia parece radicar, no obstante, en un discurso contrapuesto que se orienta a desmontar esta lectura, desnaturalizando aquello que aparece como natural en el sujeto criminal. Referimos al personaje de Stella Gibson, especialista en criminología y antropología que es convocada para colaborar con esta serie de crímenes sin aparente conexión y quien no dudará en arrojar luz sobre el accionar de Spector, pues entiende que sus motivos solo responden a una "filosofía barata" (206).

En primera instancia, las reflexiones de la protagonista cobran especial relevancia, ya que detallan la conducta de Spector desde una mirada racional que busca, asiduamente, deconstruir la existencia de un instinto asesino. Incluso, las analogías que utiliza están al servicio de una explicación más deductiva. Y de ello da cuenta cómo Gibson presenta el caso ante su equipo:

Vean esto como una adicción. Hay una ley de rendimientos decrecientes. El asesino serial, como el adicto a la heroína, siempre busca esa efusividad, y está condenado al fracaso. Por eso los periodos de reflexión se acortan y los crímenes se vuelven más elaborados. Y por eso seguirá, alimentando ese hábito de matar a menos que lo detengamos. Está claro que tiene un tipo de víctima. No son víctimas del azar, son víctimas de la elección. No lo conocen, pero él si a ellas (...) Se mueve solo, en la oscuridad, mientras, y nosotros bajo el resplandor de las luces de la prensa. Asegurémonos de no dejar ningún cabo suelto. El demonio, literalmente señores y señoras, está en los detalles. Detalles, detalles y más detalles (103).

Por lo demás, Stella representa todo aquello que Spector odia: mujeres con poder que no muestran temor ante el sujeto masculino. Consciente de ello, la detective provoca constantemente al asesino, tanto durante el proceso de caza (como, por ejemplo, cuando se desprende el escote en las conferencias de presa o utiliza el mismo color de esmalte con el que Spector pinta las uñas de sus víctimas), como también en los momentos corolarios de su captura, y que ocupan dos de las tres temporadas que componen el seriado.

Vale, por consiguiente, detenernos en dos encuentros que colaboran con nuestra lectura. Uno de ellos responde al primer diálogo telefónico entre la captora y un asesino que comienzan a ver su coartada en peligro. Dicho llamado no solo introduce el conflicto entre los 
personajes, sino que además inaugura un interrogante constante por aquello que "mueve" ("drive") a ambos sujetos. Porque, mientras Paul Spector aparece como impulsado por este confuso linde entre pulsión e instinto, Gibson se caracteriza por un fuerte pensamiento feminista que atraviesa, de principio a fin, la serie. Allí, dirán que:

Paul: La he observado con interés. Somos muy parecidos, usted y yo.

Stella: Oh, no lo creo.

Paul: Ambos impulsados (driven) por la voluntad del poder, por controlar todo y a todos. Obsesiva, despiadada, viviendo y respirando un relativismo moral. Pero usted se rige por nociones convencionales de lo correcto e incorrecto, y yo soy libre.

Stella: ¿Cómo sos libre? Sos un esclavo de tus deseos. No tenés ningún control. Sos débil, impotente. Creés que sos algún tipo de artista, pero no lo sos (...) Tratás de dignificar lo que hacés. Pero es solo misoginia. Una vieja violencia masculina contra las mujeres (105).

Stella interviene, en este contexto, como una voz femenina de lo racional: aparece para desenmascarar este imaginario del asesino como sujeto monstruoso, pues asume que "hombres como Spector son muy humanos, muy entendibles. No es un monstruo, es simplemente un hombre" (206).

Lo que aquí se pone fuertemente en cuestión es la torsión que está operando la serie al quebrar cierto pacto de lectura con este espectador que ha sido envuelto en motivos contradictorios, mientras vuelve visible otra dimensión de los sujetos que la cultura tradicionalmente ha leído como monstruosos. Porque, según atendimos, The Fall escenifica un confuso linde entre rechazo y fascinación que se ve apoyado, asimismo, por la construcción de un espectador dentro del texto, que parece verse inmerso en la polaridad de los elementos cautivantes y perversos, al mismo tiempo. Referimos a un reato que afronta un corrimiento desde la monstruosidad moral hacia los rasgos más apolíneos del personaje, e incluso hacia esta imagen de padre ejemplar, protector de los niños y amado por sus hijos. Artísticamente, se crea una ambivalencia (una "mancha de sentido", diríamos junto a Yuri Lotman) que podemos suponer pone en jaque al espectador desde el comienzo de la serie.

Por añadidura, The Fall involucra discusiones relativas a la construcción de los géneros y al modo en que las ficciones de asesinos seriales parecen naturalizar no solo la figura del criminal (reiteradamente masculino), sino además el lugar de la víctima. Es por ello que, ante esta extraña atracción que Spector genera en sus colegas, Gibson reflexionará que:
Una mujer, no recuerdo quién, una vez le preguntó a un amigo qué es lo que más temen los hombres ante las mujeres. Respondió que temían que las mujeres se rieran de ellos. Al preguntarles a las mujeres qué temían ante los hombres, dijeron: "tememos que nos maten". Podrá fascinarte a ti. Yo lo detesto con cada fibra de mi ser (206).

Adviene, por otra parte, un segundo encuentro: el interrogatorio que Stella le realiza a Spector, y en el que, tiempo después, se responde aquella pregunta retórica que la detective formulara al comienzo, " ¿alguna duda sobre el género de la persona responsable? Entonces, no perdamos tiempo buscando a una mujer" (103). Repleto de silencios y pausas, este primer intercambio cara a cara toma la forma de un extenso diálogo denso en información, en donde, una vez más, Gibson interpelará la conducta del asesino:

Stella: ¿Qué convirtió a Sarah Kay en una víctima, y no, digamos, Olivia?

Paul: Ella es mi hija.

Stella: Todas tus víctimas son hijas (...) ¿De dónde salió tu odio por las mujeres? (...) ¿Cuándo comenzaron a volverse violentos tus impulsos sexuales? ¿Infringís actos sexuales contra ellas?

Paul: No soy un violador.

Stella: Las violás. Sos un violador.

Paul: No realizo actos sexuales explícitos con mis víctimas. Stella: Te impulsan (drive) las fantasías sexuales y las manifestás con fuerza (...) ¿Cómo te sentís después? ¿Culpa? ¿Vergüenza? ¿Remordimiento? ¿Miedo? Debés sentir miedo (206).

Al tiempo que reafirma su hipótesis de que la violencia masculina recae en un temor no expreso de los hombres hacia las mujeres, Stella enfatiza en la misoginia como respuesta racional ante el devenir asesino, poniendo además en tela de juicio el carácter excepcional del afecto que Spector siente por su hija. Hay, de este modo, una fuerte crítica a la diferencia de géneros en la contemporaneidad, mediante esta protagonista que rompe con los esquemas canónicos. Se trata de un personaje que vive su sexualidad con libertad (entiende que su deseo sexual y su preferencia tanto por hombres como por mujeres no interviene en su oficio), pero que, sin embargo, en su labor como agente policial, sufre asiduamente una serie de micromachismos e incluso el ataque de un jefe que intenta propasarse sexualmente. De allí que Stella, sintetizando su pensamiento y su postura ante el contexto social que vive, le afirme a una de sus colaboradoras que "hemos elegido trabajar en una cultura masculina, paramilitar y patriarcal. No dejemos que nos ganen" (202).

Desde nuestra lectura, todo ello aparece al servicio de 
desmontar lo que la protagonista asume como el "instinto de toda mujer" (302). Referimos a esta construcción cultural de un imaginario que, también, asume lo instinto como andamiaje explicativo para todo un orden de lo femenino. Como hemos anunciado en investigaciones previas (Gómez Ponce, 2017), allí ingresan prácticas que la cultura, tradicionalmente, asume como lugares comunes de la biología de la mujer: la sexualidad (y, con ello, las reminiscencias de la seducción femenina), la maternidad y la necesidad de protección son, de manera ejemplar, los motivos más recurrentes en esta naturalización.

Stella Gibson, en tal sentido, se contrapone a este discurso canónico de corte patriarcal, con el objeto de desafiar las convenciones en los géneros que cartografía la cultura mediante, por ejemplo, los medios de comunicación. De manera particular, ello se expresa en su reproche ante el modo en que la Policía de Belfast devela información ante la prensa local:
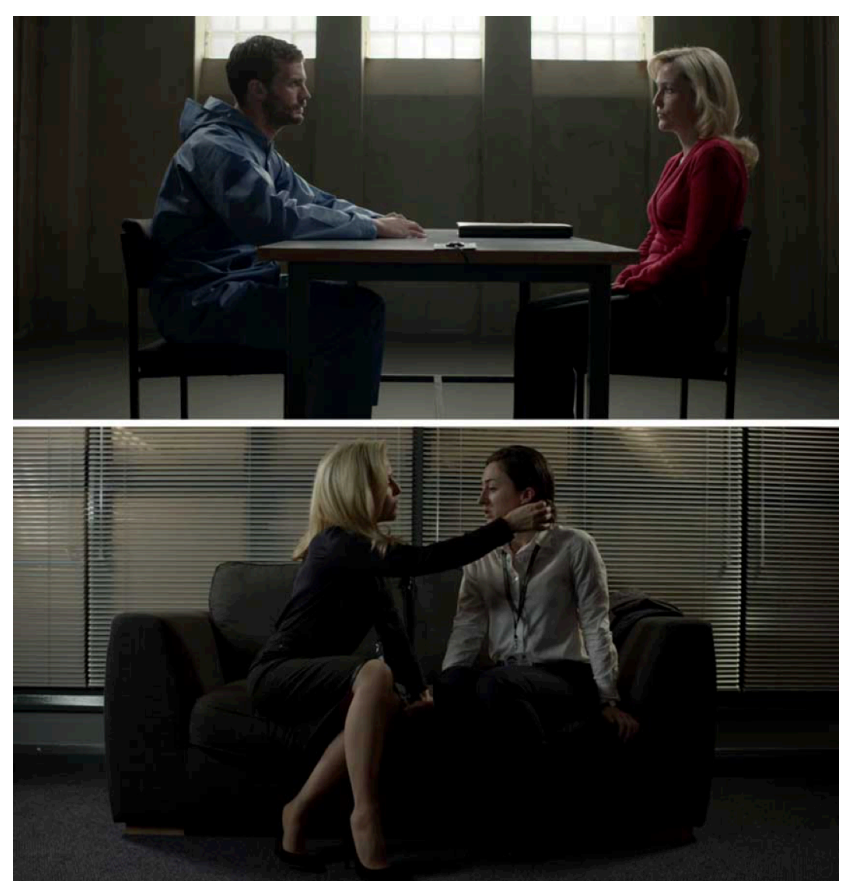

Imagen 5. Arriba: captura de pantalla del interrogatorio de Stella Gibson (Gillian Anderson). Abajo: captura de pantalla de los coqueteos de la detective con otras mujeres. Cubitt, A.; Verbruggen, J. (2013) The Fall. Reino Unido: BBC Northern Ireland.

No nos refiramos a ellas como inocentes (...) ¿Qué pasa si la siguiente es una prostituta? ¿O una mujer volviendo a casa borracha, tarde a la noche, con una falda corta? ¿Serían, de alguna manera, menos inocentes y, por ello, lo merecen? ¿Culpables? Los medios aman dividirlas mujeres en vírgenes y vampiresas, ángeles y putas. No los alentemos (103).
De lo que se trata, en otras palabras, es de una serie que se esfuerza por demostrar que la perversión del asesino serial no está solo en él, sino además en un sistema machista que caracteriza a la comunidad irlandesa. ${ }^{7}$

Por lo demás, nada casual resulta, en consecuencia, que el instinto emerja como un andamiaje explicativo, en tanto su plasticidad le permite traducir un amplio caudal de prácticas que rotulan un "vacío" entre los ejes opositivos humano/monstruo y masculino/femenino, pero que la narrativa en cuestión estar orientada a resolver. Esta lógica nos impulsa a sugerir que The Fall guarda, en su interior, cierta estructura de perfil criminológico y, al mismo tiempo, de novela pedagógica: ello es, un relato que narra las operatorias del asesino serial, en un intento por dilucidar su conducta, como si ello buscara advertir al espectador de estas perversiones que se esconden en la misma cotidianeidad. Valga como ejemplo final aquel diálogo en el que el asistente de Stella se intenta justificar ante ella, afirmando que Spector "parecía un buen tipo, inteligente, agradable. No parecería tener que ocultar nada”; ella, por su parte, replicará enfurecida que “¿qué les he estado diciendo sobre estos sujetos? Frecuentemente, aparentan ser encantadores, inteligentes y carismáticos. La palabra clave es 'aparentan'” (202).

Por los indicios señalados, intuimos que el relato individual del asesino serial acaba siendo, por refracción múltiple, una forma de relato colectivo, que muestra la imposibilidad de plantear la problemática del instinto sin recalar finalmente en el tema de las identidades sexuales y los regímenes culturales que las sostienen. The Fall deviene, por lo tanto, una narrativa aleccionadora sobre las condiciones de posibilidad que le permiten al instinto rotular comportamientos que los sistemas excluyen de sus paradigmas. Podemos pensar, entonces, que la pregunta no es tanto "qué es un instinto", sino más bien cuáles son las condiciones que permiten que ciertos sujetos califiquen dentro de tal. La respuesta aparecería a la luz de un conjunto de problemas situados en múltiples fronteras donde las prácticas que la cultura formula como "anormales" y las formas de la ficción parecen traducirse mutuamente. También, en esta reintroducción constante de un poroso umbral donde bagaje biológico y orden social se desarrolla como el conflicto central para pensar la construcción artística de las subjetividades. En tal sentido, la reflexión sobre lo instintivo en ciertos recorridos estéticos pone de manifiesto cómo, al tiempo que expresa un caudal de pensamientos cotidianos, el arte interpela conglomerados de valores éticos y tradicionales que sostienen nuestra cultura. 


\section{Reflexiones finales}

En su desenlace, The Fall se concretiza como una serie desoladora. La estadía en el psiquiátrico (a causa de una fingida amnesia) y el final suicidio de Spector ponen en escena el fracaso de una Stella Gibson que, asiduamente, se repite: "no quería que terminará aquí. No así. No sin juicio, sin sentencia, sin castigo, si un cierre para las familias. Lo quiero vivo, así puede ser enjuiciado, sentenciado y pasar el resto de su vida en prisión" (301). Se trata, en otras palabras, de la derrota de una mujer que no ha podido vencer al sistema patriarcal, y de un criminal cuyos "instintos" logran, a su manera, triunfar.

Sin embargo, la narrativa en cuestión nos permitió emprender un recorrido analítico, dedicado a explicar la complejidad que guarda este "instinto asesino" tan recurrente en las ficciones actuales. En su cartografía de una zona conflictiva y confusa, el instinto apareció como fragmento de un imaginario que recorre nuestro orden social contemporáneo, pero también como un lugar común que orienta insistentemente las operaciones estéticas de series como The Fall. Ello evocó un despliegue de reflexiones que, en futuros recorridos, nos orientará a la hora de abordar diversas textualidades concretas en las cuales los sujetos son naturalizados o "traducidos" en otros términos instintivos. Visto desde una distancia crítica, resulta necesario, entonces, repensar qué significa y cómo se significa el instinto, término que se ha cargado de conformismo y es pacíficamente aceptado para explicitar intuiciones, impulsos, corazonadas y reflejos, pero también excesos e inclinaciones que parecen provenir de un eslabón biológico desconocido.

Diremos, por ello, que series como The Fall están operando como una "tecnología de instintos": una compleja trama de relaciones discursivas, organizadoras y restrictivas que arrostran los mecanismos para la interpretación (pero, también, el tratamiento y la corrección) de una intervención ficcional del instinto. Este andamiaje semiótico, operado por ficciones televisivas, pone en evidencia que la sociedad contemporánea es coercitiva y construye a determinados sujetos "biológicamente" desde redes de poder, mandatos morales y sistemas de valores que delimitan roles, al tiempo que dan cuenta de línea de fuga que ofrecen una fuerte crítica social.

Desde esta comprensión, los textos artísticos legitimarían todo un aparato de producción corporal, como un nudo semiótico que rotula y ordena prácticas, cuerpos e identidades, según jerarquías sociales y sistemas de normalización y normalización. Con todo, resuenan nuevamente las palabras de Michel Foucault (2014), quien nos invita a seguir indagando sobre la necesidad imperante de "pensar el instinto no como un dato natural, sino como una elaboración; todo un juego complejo entre el cuerpo y la ley, entre el cuerpo y los mecanismos culturales" (p. 51).

\section{Referencias}

Ardrey, R. (1976) La evolución del hombre: la hipótesis del cazador. Madrid: Editorial Alianza.

Bakhtin, M. (2008[1953]) “El problema de los géneros discursivos”. En Estética de la Creación Verbal. Buenos Aires: Siglo XXI. P. 245-290.

Bartra, R. (2013) Antropología del cerebro. Conciencia, cultura y libre albedrío. Barcelona: Pre-Textos.

Bateson, G. (1998[1985]) Pasos hacia una ecología de la mente. Buenos Aires: Lumen-Lohlé.

Besuschio, A. (2014) “Prólogo”. En Bafico, Jorge. El origen de la monstruosidad. Buenos Aires: Indicios. P. 3-18.

Blumberg, M. (2005) Basic Instinct: The Genesis of Behaviour. New York: Thunders Mouth Press.

Cubitt, A. [creador]; Verbruggen, J. [director] (2013) The Fall [serie televisiva]. Reino Unido: BBC Northern Ireland.

Dawkins, R. (2002[1976]) El gen egoísta. Las bases biológicas de nuestra conducta. Barcelona: Salvat.

De Waal, F. (2013) El bonobo y los diez mandamientos. En busca de la ética entre los primates. Buenos Aires: Tusquets Editores.

Foucault, M. (2002) Los anormales. Curso en el Collège de France 1974-1975. Buenos Aires: Siglo XXI.

Foucault, M. (2014) Las redes de poder. Buenos Aires: Prometo Libros.

Freud, S. (1989[1920]) “Beyond the Pleasure Principle”. En The Frend Reader. Traducción por Peter Gay. New York: Norton \& Company Inc. P. 594-625.

Fromm, E. (1975) Anatomía de la destructividad bumana. México: Editorial Siglo XXI.

Gallardo, M. (2011) Evolución. El curso de la vida. Buenos Aires: Panamericana. 
Gómez Ponce, A. (2017) Depredadores. Fronteras de lo humano y series de TV. Córdoba: Editorial Babel.

Hoffmeyer, J. (2011) “Biology is Immature Biosemiotics”. En Kull, Kalevi y Emmeche, Claus [Eds.]. Towards a Semiotic Biology. Life is the Actions of Sings. Londres: Imperial College Press. P. 43-66.

Kristeva, J. (2001) Historia de amor. Buenos Aires: Siglo XIX.

Lapanche, J. y Pontalis, J. (1996). Diccionario de psicoanálisis. Buenos Aires: Paidós.

Lorenz, K. (1975[2005]) Sobre la agresión: el pretendido mal. México: Siglo XXI.

Lotman, Y. (1990) The Universe of the Mind. Londres: Indiana University Press.

Lotman, Y. (1978[1998]) “El fenómeno de la cultura”. En La Semiosfera II. Madrid: Ediciones Frónesis Cátedra. P. 25-41.

Ressler, R. et al (2005) Crime Classification Manual. A Standard System for Investigating and Classifying Violent Crimes. Segunda edición. San Francisco: Jossey-Bass Publishing.

Rosa, N. (2006) Relatos críticos. Cosas, animales, discursos. Buenos Aires: Santiago Arcos.

1 Será en el curso Los anormales, dictado en el Collège de France entre 1974 y 1975, en donde Foucault se preocupe por recorrer el camino trazado por tres figuras que, aunque nunca de manera sincrónica, cobran visibilidad en el contexto histórico de sus amores, y promueven vectores para entender las lógicas de lo anormal: el individuo a corregir (y su correlación con la domesticación del cuerpo y los comportamientos), el onanista (en el marco de las relaciones sexuales y las formas de corrección de prácticas, tales como la masturbación) y el monstruo humano, aquella que nos convoca en este trabajo. Aún a riesgo de simplificar, aunque históricamente el monstruo ha escenificado la ruptura de la ley (transgresión hartamente replicada por el arte, principalmente el medieval), Foucault observa una nueva idea de monstruosidad en el siglo XIX, a partir de la transición que el término surca desde su comprensión mitológica (y el filósofo piensa, especialmente, en la fábula de Pulgarcito) e incluso físico-biológica (en casos como el hermafroditismo), a una forma de anomalía social que remite a aquellas figuras que no difieren del hombre común, pero que suponen siempre una amenaza para el orden cultural. Al respecto, Véase Foucault 2002, p. 107-108

2 Resulta pertinente destacar que esta lectura evolucionista ha sido hartamente discutida, incluso dentro del mismo campo de la biología (Cfr. Gallardo, 2011). Según observamos previamente, los estudiosos coinciden en que su propagación se debe a uno de sus principales referentes: el zoólogo inglés Richard Dawkins (1976[2002]) quien, interrogándose por la unidad de la evolución (la especie, la población o el individuo), solidificó este imaginario al proponer su reconocida de teoría en torno a un descubrimiento entonces reciente, el gen. Su hipótesis central sostuvo que todo ser estaría programado para reproducirse, en tanto mero recipiente de genes que buscan incansablemente replicarse. Al respecto de estas relecturas que han dado lugar a un darwinismo canónico y las influencias que ellas han tenido en una comprensión determinista que aun circula por la cultura contemporánea, Véase Gómez Ponce, 2017.

3 Se trata, en otras palabras, del afán de los científicos por hallar un “Adán prehistórico”: ello es, un eslabón perdido que explicaría el paso hacia la alimentación carnívora y el nacimiento de un "instinto de la agresividad”. Al respecto, Véase la "hipótesis del cazador” del antropólogo estadounidense Robert Ardrey (1976). Si Darwin tenía razón y nuestra especie descendía de los primates, la antropología y la paleontología de mediados del siglo XX estaban convencidas de que los restos arqueológicos y fósiles podrían confirmar la idea del padre de la biología. De modo que, descubrir el camino evolutivo de un instinto cazador permitiría dar con el famoso eslabón perdido que sellaría la discontinuidad entre mundo natural y cultural. No obstante, ante la escasez de hallazgos y dentro del rompecabezas que supone nuestra historia biológica, las hipótesis se esgrimieron con base en exiguas evidencias paleontológicas, generando confusas ideas que circularon masivamente por los discursos de divulgación (De Waal, 2013)

4 En su estudio sobre las formas del placer y el displacer sexual, Freud (1920[1989]) propone la noción de “pulsión”, diferenciándola del instinto etológico, en tanto su objeto no se determina por la biología, sus modalidades para satisfacer son variables (ligadas a las zonas erógenas) y se presenta fragmentada (está ligada a representaciones y fantasías que son transformadas por la libido, esta energía fundamental en el edificio teórico freudiano). El problema surge cuando esta distinción (clara en la lengua alemana: mientras el Instinkt remite al comportamiento animal, el Trieb da cuenta de un proceso dinámico a medio camino entre lo anímico y lo somático), en inglés dicha diferenciación es omitida, apareciendo solo la palabra instinct. Como indican bien los estudiosos Laplanche y Pontalis (1996), al prescindir de términos más equivalentes (como drive o urge, que subrayarían más la orientación que la finalidad), "la elección del término instinto como equivalente de Trieb no es solamente una inexactitud de traducción; además ofrece el peligro de introducir una confusión entre la teoría freudiana de las pulsiones y las concepciones psicológicas del instinto animal” (p.198)

5 La codificación utilizada para anotar las citas de las series se organiza del siguiente modo: la primera cifra indica la temporada y las dos siguientes, el número de capítulo. Por ejemplo, 203 (tercer episodio de la segunda temporada). Asimismo, las traducciones de diálogos son nuestras, basada en el subtitulado ofrecido por el sitio de streaming Netflix

6 Este rasgo del presente narrativo del personaje se comprenderá a la luz de su pasado, particularmente desde una infancia traumática en la que un joven Spector vio suicidarse a su madre y pasó junto al cadáver varios días, para luego ser llevado a un orfanato en donde sufrirá abusos sexuales. Y vale señalar que esta inclusión supone un lugar de interés, por tanto otra series también parecen estar preocupadas por relatar el abuso infantil en Irlanda, país que se caracteriza por una fuerte influencia de la Iglesia Católica. 
Tal es el caso de la serie Sons of Anarchy (FX, 2008-2014), que ficcionaliza una comunidad de moteros de descendencia irlandesa que, además de financiar al IRA mediante la venta ilegal de armas, narran las influencias del catolicismo y los casos de pedofilia por parte del clero. O, también, Ray Donovan (Showtime, 2013), protagonizada por un “solucionador de problemas" de celebridades hollywoodenses, acosado por los fantasmas de un pasado en el cual él y sus dos hermanos fueron violados por curas, durante su crecimiento en el barrio irlandés de Boston, Southie

7 Y aunque de ningún modo resulte pertinente detenernos aquí en estadísticas, vale mencionar que, según informa el diario irlandés The Journal, hablamos de una sociedad en donde el $96 \%$ de las llamadas diarias a la policía es realizada por mujeres que sufren violencia doméstica (además de ocupar ellas una posición de inferioridad social: por ejemplo, ganan un cuarto menos de sueldo que los hombres y solo el 10\% accede a los cargos políticos, pues su ejercicio laboral está recluido casi exclusivamente a la educación y la salud). Al respecto, Véase http://www.thejournal.ie/gender-cso-report-ireland-1594492-Jul2014/. También, en vinculación a la violencia doméstica: http://www.thejournal.ie/reports-of-domestic-violence-to-women-and-children-up-by-5000-3393394May2017/ [Consultados el 24 de febrero de 2018] 